personnel who do not have direct contact with asbestos in their jobs, the increase in risk depends essentially on the ship's year of arming and the presence of asbestos, whether or not on board, as well as the duration of exposure of seafarers.

Conclusion These results allow us to recommend a classification of the risk in accordance with the recommendations of the french health authority and to propose an adequate post professional follow up for soldiers of the French Navy.

\section{HORSE STABLES AS POTENTIAL SOURCE OF FUNGAL EXPOSURE TO OFFICE WORKERS}

1,2Tanusha S Singh*, 1,20nnicah D Matuka. 'National Institute for Occupational Health, National Health Laboratory Services, Johannesburg, South Africa; ${ }^{2}$ Department of Clinical Microbiology and Infectious Diseases, University of Witwatersrand, Johannesburg, South Africa

\subsection{6/oemed-2018-ICOHabstracts.556}

Introduction Workers spend considerable time in office buildings which are generally considered to be low risk environments. However, under favourable conditions (e.g. poor housekeeping, inadequate ventilation, poorly regulated temperature and relative humidity; nutrient substrates), indoor microbial levels may increase. Therefore indoor air quality (IAQ) becomes an important factor for workers health. This investigation examined air quality in offices situated one floor above the horse stables and evaluated the association with reported respiratory symptoms among office workers.

Methods Air sampling by impaction method onto agar plates was done for fungal detection. Fungi were identified using microscopy and BIOLOG system (metabolic fingerprinting). Environmental parameters (temperature, relative humidity, carbon dioxide) were measured using the IAQ monitor. Sampling was repeated (before and after cleaning intervention) in the offices near the horse stables (vaccine production). Employees completed a questionnaire on medical and occupational history.

Results Air measurements showed high concentrations (155$1720 \mathrm{cfu} / \mathrm{m}^{3}$ ) of allergenic fungi. The most common genera isolated were Aspergillus, Penicillium, Fusarium, Trichoderma and Paecilomyces. The average fungal counts after cleaning the offices were threefold $\left(954 \mathrm{cfu} / \mathrm{m}^{3}\right)$ than before the rigorous cleaning process $\left(303 \mathrm{cfu} / \mathrm{m}^{3}\right)$. Office occupants complained of bad odour which worsened during the day. Symptoms reported by workers were nose irritation (60\%), sinus congestion and headache (40\%); and eye irritation and dry throat $(30 \%)$. Symptoms worsened at work but improved when away from the office.

Conclusion Increased viable concentrations of airborne fungi in offices and high counts after cleaning indicated stables as a source of fungal contamination. The movement of horses between the stable and the paddock creates a lot of dust which is the likely mode of transmission to the offices. Some employees reported symptoms suggestive of those caused by the fungal genera identified. No complaints were received after the horse stables were relocated in keeping with local by-laws.

\section{CHEMICAL INTOLERANCE IS NOT A GOOD PREDICTOR OF WORK RELATED SYMPTOMS AMONG FINNISH OFFICE WORKERS}

Jari H Stengård*, Sanna Lappalainen, Jouko Remes, Markku Sainio. Finnish Institute of Occupational Health, Helsinki, Finland

\subsection{6/oemed-2018-ICOHabstracts.557}

Introduction Chemical intolerance (CI) is a condition characterised by series of symptoms that affected persons attribute to exposure to low levels of several identifiable or unidentifiable substances commonly present in environment. Many of the symptoms are general symptoms, such as dizziness, fatigue, headache and difficulties to concentrate that are present in many medical conditions and illnesses. Similar symptoms are attributed to poor indoor air quality, for instance. In this study we evaluate:

- occurrence of CI among Finnish office workers and

- whether identified CI individuals have work related symptoms.

Methods The study population comprises 174 office workers recruited in connexion with our Multispace Office (MOSI) project. The participants work in six different workplaces, of which none had known abnormal sources of indoor air impurities. The Chemical exposure-section of Quick Environment Exposure Sensitivity Inventory (QEESI) questionnaire was employed to identify CI individuals and modified MM-40 (Örebro) questionnaire to evaluate their work related symptoms.

Results We identified altogether 52 (30\%) CI individuals as indicated by their QEESI questionnaire score (score $\geq 40$ ). Of them $21(40 \%$ versus $18 \%$ in individuals with QEESI score $<40$, p <0.002) reported that they have had irritation symptoms in throat, nose or eyes at work and 29 (56\% vs 39\%, $\mathrm{p}=0.511$ ) had general symptoms, such as fatigue, headache, feeling heavy head or difficulties in concentrating. Probability of irritation symptoms among CI individuals is $40 \%$.

Discussion Our findings are in line with earlier observations that prevalence of chemical intolerance may be up to $33 \%$. Occurrence of IC was associated with irritation symptoms but not general symptoms. However, its positive predictive value (i.e. proportion of irritation symptoms among CI individuals, $40 \%$ ) was not much better than prevalence of irritation symptoms among office workers (25\%) suggesting that CI is not very good predictor of work related symptoms among Finnish office workers.

\section{IMPROVEMENT OF DETERMINATION METHOD FOR ETHYLENE GLYCOL IN THE AIR OF WORKPLACE BY CAPILLARY GAS CHROMATOGRAPHY}

Zhonglin Zhao, Cheng Cao. Shanghai Institute of Occupational Disease for Chemical Industry, Shanghai, China

\subsection{6/oemed-2018-ICOHabstracts.558}

Introduction Ethylene glycol, which is colourless and odourless, is widely used in the field of manufacture of coolant, 
antifreeze, synthetic polyester and resin, etc. Although ethylene glycol is a compound with low toxicity, cases concerning the damage of glycol to central nervous system and respiratory system occur frequently because of its widely use. Long-term exposure under the workplace air with ethylene glycol can lead to coma, heart-failure and even death. The recommended method for the determination of ethylene glycol in the air of workplace ruled in current standard of government (GBZ/T 160.48-2007) has a detection limit of $14 \mathrm{mg} / \mathrm{m}^{3}$. Considering the occupational exposure limit (PC-TWA) of ethylene glycol given by China's Ministry of Health is $20 \mathrm{mg} / \mathrm{m}^{3}$, there is a risk of 'once detection, beyond limit already'. So an improved method with higher sensitivity and lower detection limit should be established to meet the need of practical application.

Methods Ethylene glycol in the air of workplace was collected by solid sorbent tube containing silica gel and desorbed by solvent in the lab. The thus abtained sample was determined by capillary gas chromatography with FID detector. The performance of different kinds of desorption solvent and capillary column was investigated, and the condition of analysis was also optimised. Furthermore, the parameters of the improved method such as detection limit and precision were analysed.

Results As desorption solvent, methanol exhibited best performance with high desorption efficiency and equilibrium speed. And DB-WAXetr is the most suitable capillary column, as ethylene glycol showed stable retention time and sharp peak with good symmetry on it. The regression equation showed a good linear relationship in the range of $0.05-$ $1.0 \mathrm{mg} / \mathrm{mL}$. The detection limit of the method was $0.92 \mathrm{mg} /$ $\mathrm{m}^{3}$ and the precision is $1.5 \%-4.2 \%$.

Conclusion An improved method for the determination of ethylene glycol by capillary gas chromatography was developed. The method is simple, rapid and accurate with wide linear range. Compared with the traditional recommended method, the sensitivity of the novel method was greatly improved with a much lower detection limit of $0.92 \mathrm{mg} / \mathrm{m}^{3}$. The new method is more suitable and reliable for the determination of ethylene glycol in the air of workplace.

\section{INDOOR AIR CONDITIONS OF OFFICE ROOM IN WINTER}

TANAKA Masatoshi. Fukushima Medical University

\subsection{6/oemed-2018-ICOHabstracts.559}

The climate in Japan is generally cool/dry in winter and hot/humid in summer. Winter season is from December to February in Japan. January is the coldest month. We measured indoor air conditions; air temperature, humidity and carbon dioxide (CO2) during 12 months at the office room of one manufacturing industry $(800$ workers). The office hour at this office is from 8:30 to $17: 30$. Average mean value ( \pm standard deviation) of room air temperature in January was $20.3 \pm 3.1^{\circ} \mathrm{C}$, humidity was $32.8 \% \pm 3.5 \%$ and $\mathrm{CO} 2$ was $924.5 \pm 478.2 \mathrm{ppm}$. Average room air temperature at office hour was $24.0 \pm 0.8^{\circ} \mathrm{C}$, maxi/mini air temperatures were $25.1 / 22.2^{\circ} \mathrm{C}$, average humidity was $38.8 \% \pm 2.5 \%$, maxi/mini humidity was $41.3 / 33.7 \%$ and average CO2 was 1350.9 $\pm 228.3 \mathrm{ppm}$, maxi/mini CO2 were $1563 / 792 \mathrm{ppm}$. Setting room air temperature of $25^{\circ} \mathrm{C}$ comprised the highest frequency at air conditioners at this office. Regarding the recommend levels for air conditions in office buildings, air temperature is $17^{\circ} 28^{\circ} \mathrm{C}$, relative humidity is $40 \sim 70 \%$ and CO2 is 1000 ppm during all seasons. As
Conclusion, the room air temperatures at office hour were rather high and humidity levels were low. We recommend setting room air temperature level for energy conservation and health is $17^{\sim} 20^{\circ}$ $\mathrm{C}$, and humidity is about $50 \%$ in winter.

\section{FRAGRANCES/ODOURS IN INDOOR AIR AND HEALTH EFFECTS?}

Peder Wolkoff. National Research Centre for the Working Environment, Lersø Parkallé 105, 2100 Copenhagen, Denmark

\subsection{6/oemed-2018-ICOHabstracts.560}

Introduction On-line interviews of the general population have shown excessive prevalence of health effects stipulated to be caused by inhalation of fragrances, e.g. from consumer products.

Method Four major abundant and common airborne fragrances in indoor air have been reviewed. Their impact on perceived indoor air quality, sensory irritation effects, and sensitisation in the eyes and airways has been assessed. Further, effects on breathing pattern, cardiovascular system, work performance, and the impact in the airways by ozone-initiated fragrance reactions have been reviewed.

Results Maximum reported indoor concentrations of the fragrances are close to their odour thresholds. The concentrations are orders of magnitude lower than their thresholds for sensory irritation. Risk values for long-term effects are also above reported indoor concentrations. Human exposure studies and supported by animal inhalation models do not support sensitisation of the airways at indoor levels. Effects on the breathing rate and mood are inconclusive. Some fragrances may increase the high-frequency heart rate variability, but reduction may occur by aerosol exposure during cleaning activities. Distractive effects that influence the work performance are consistently reported, but their persistence is unknown. There is insufficient information that ozone-initiated reactions with fragrances cause airway effects at indoor levels; contrary, beneficial effects in sensitised animals have been observed.

Discussion Common health effects obtained from on-line interviews are inconsistent with experimental data. In general, lung function and sensory effects are likely due to the 'odour' perception rather than toxic effects of the fragrances. Furthermore, sensitisation by inhalation is not supported by animal studies. The substantial discrepancy between the high prevalence of reported health effects as opposed to lack of experimental support is a continuing challenge; strategies to solve this should be developed, e.g. targeted information about volatile organic compounds and their health effects in indoor air.

\section{EVALUATING AMBIENT AND INDOOR AIR QUALITY OF HOUSEHOLDS IN A METRO MANILA COMMUNITY AFTER A BELOW GROUND PETROLEUM PIPELINE SPILL}

Joselito L Gapas. First Philippines Industrial Corporation, Pasig City, Metro Manila, Philippines

\subsection{6/oemed-2018-ICOHabstracts.561}

Introduction First Philippines Industrial Corporation (FPIC) owns an underground petroleum pipeline bringing refined petroleum products to a depot in MetroManila. In 2010, an 